\title{
Caracterização ambiental do uso e ocupação do solo das áreas de influência em municípios da Rota de Integração Latino-Americana
}

\author{
Environmental characterization of land use and occupation of areas of influence \\ in municipalities of the Latin American Integration Route \\ Caracterización ambiental del uso y ocupación del suelo de las áreas de \\ influencia en municipios de la Ruta de Integración Latino-americana
}

\author{
Mariana Antonio de Souza Pereira ${ }^{1}$ \\ Fernando Jorge Corrêa Magalhães Filho ${ }^{1}$ \\ Ana Paula Silva Teles ${ }^{1}$ \\ Fabio Martins Ayres ${ }^{1}$
}

Recebido em 09/09/2018; revisado e aprovado em 12/01/2019; aceito em 12/04/2019

DOI: http://dx.doi.org/10.20435/inter.v20iespecial.2147

\begin{abstract}
Resumo: A análise ambiental é fundamental para reconhecer as potencialidades e vulnerabilidades da região investigada. Baseado em imagens de satélites, o estudo buscou analisar o uso e a ocupação do solo em municípios que fazem parte do Corredor Bioceânico localizado no Estado do Mato Grosso do Sul e que também possuem territórios inseridos na Bacia do alto Paraguai. Constatou-se que em média $60 \%$ dos municípios tiveram parte de sua vegetação nativa substituídas por monoculturas e pastagens exóticas.
\end{abstract}

Palavras-chave: BAP; corredor bioceânico; mapeamento; uso e ocupação do solo.

Abstract: The environmental analysis is fundamental to recognize the potentialities and vulnerabilities of the region investigated. Based on satellite images, the study sought to analyze the use and occupation of the soil in municipalities that are part of the Bioceanic Highroad Crossing located in the State of Mato Grosso do Sul and that also have territories inserted in the Upper Paraguay Basin. It was found that on average $60 \%$ of the municipalities had part of their native vegetation replaced by monocultures and exotic pastures.

Keywords: BAP; bioceanic highroad crossing; mapping; use and occupation of the soil.

Resumen: El análisis ambiental es fundamental para reconocer las potencialidades y vulnerabilidades de la región investigada. En base a imágenes de satélites, el estudio buscó analizar el uso y la ocupación del suelo en municipios que forman parte del corredor bioceánico ubicado en el Estado de Mato Grosso do Sul y que también poseen territorios insertados en la Cuenca del alto Paraguay. Se constató que en promedio el 60\% de los municipios tuvieron parte de su vegetación nativa sustituida por monocultivos y pastos exóticos.

Palabras clave: BAP; corredor bioceánico; mapeo; uso y ocupación del suelo.

\section{INTRODUÇÃO}

Devido à necessidade da crescente demanda de produtos, insumos e serviços, a economia globalizada contemporânea busca novos meios de atendimento a mercados em potencial, através de vias confiáveis e rápidas. Assim os corredores bioceânicos foram criados com o objetivo de facilitar o comércio, fomentar a comunicação entre regiões diferentes, como também proporcionar o desenvolvimento e infraestrutura.

Em virtude desses novos desafios econômicos e sociais, por muitas vezes as questões ambientais foram examinadas em segundo plano, mas com o aprimoramento e o desenvolvimento de novas tecnologias como também instrumentos normativos, possibilitam uma análise mais específica dessas questões.

\footnotetext{
${ }^{1}$ Universidade Católica Dom Bosco (UCDB), Campo Grande, Mato Grosso do Sul, Brasil.
} 
As geotecnologias são ferramentas que auxiliam no diagnóstico, no monitoramento e na avaliação dos impactos causados ao meio ambiente, dentre elas se destacam o geoprocessamento e os sistemas de Informação Geográficas (SIG). Com isso se faz possível a associação de dados cartográficos e de imagens obtidas por sensores remotos, que são capazes de registrar a radiação eletromagnética refletida pelos elementos de vegetação, para quantificação da biomassa florestal e alvos da superfície terrestre (ROSA, 2005; MACEDO, 2009; PONZONI; REZENDE, 2004).

Alguns estudos têm sido realizados com o objetivo de determinar os impactos sobre os recursos naturais, resultante do uso impróprio da capacidade natural da terra, que vem comprometendo a vegetação. Por meio de uma análise do monitoramento do desmatamento do pantanal mato-grossense através de imagens de satélite, Ferreira e Pasa (2015) buscaram obter informações sobre a real situação da cobertura vegetal do bioma. Também utilizando imagens de satélite, Pessoa et al. (2013) investigaram a evolução da cobertura vegetal e do uso da terra na Interbacia do Rio Paraguai Médio-Mato Grosso, para identificação, mapeamento e quantificação classes de uso e cobertura da terra. Através de séries temporais de dados do satélite EVI/ MODIS , Antunes Esquerdo e Lamparelli (2011) realizaram o monitoramento de quatro áreas com diferentes coberturas vegetais no Pantanal.

Rosa et al. (2009) verificaram a correlação entre a distribuição de caranguejos com a proximidade do Rio Cuiabá e a cobertura vegetal em alagados do Pantanal Mato-grossense, por meio da coleta de espécimes no período de chuva. Em uma análise da complexidade e heterogeneidade da paisagem do Pantanal, Miranda et al. (2018) através de imagens de índice de vegetação por diferença normalizada (NDVI), contataram que o uso de NDVI na estimativa de parâmetros da paisagem é uma ferramenta eficiente para o reconhecimento e monitoramento da complexidade e heterogeneidade de habitats do Pantanal, replicável em outras regiões.

Sendo assim, o estudo busca contribuir na análise de uso e a ocupação do solo em municípios que fazem parte da Rota de Integração Latino-Americana (RILA), também conhecida como Corredor Bioceânico, em Mato Grosso do Sul, e que também possuem territórios inseridos na Bacia do alto Paraguai, baseado em imagens de satélites, a fim de verificar, identificar e quantificar as classes de uso do solo.

\section{METODOLOGIA}

O presente estudo buscou analisar o uso e ocupação do solo nos municípios que fazem parte do Corredor Bioceânico e da Bacia do Alto Paraguai, porção brasileira (BAP). Os municípios de Porto Murtinho, Jardim, Guia Lopes da Laguna, Nioaque, Anastácio, Dois Irmãos do Buriti estão totalmente inseridos na BAP. Apenas os municípios de Sidrolândia, Campo Grande e Maracaju apresentam menos de $25 \%$ de seu território inserido na bacia hidrográfica, apresentados na Figura 1. 
Figura 1 - Localização da área de estudo, destacando os municípios do estado de Mato Grosso do Sul e o limite da Bacia do Alto Paraguai (BAP)

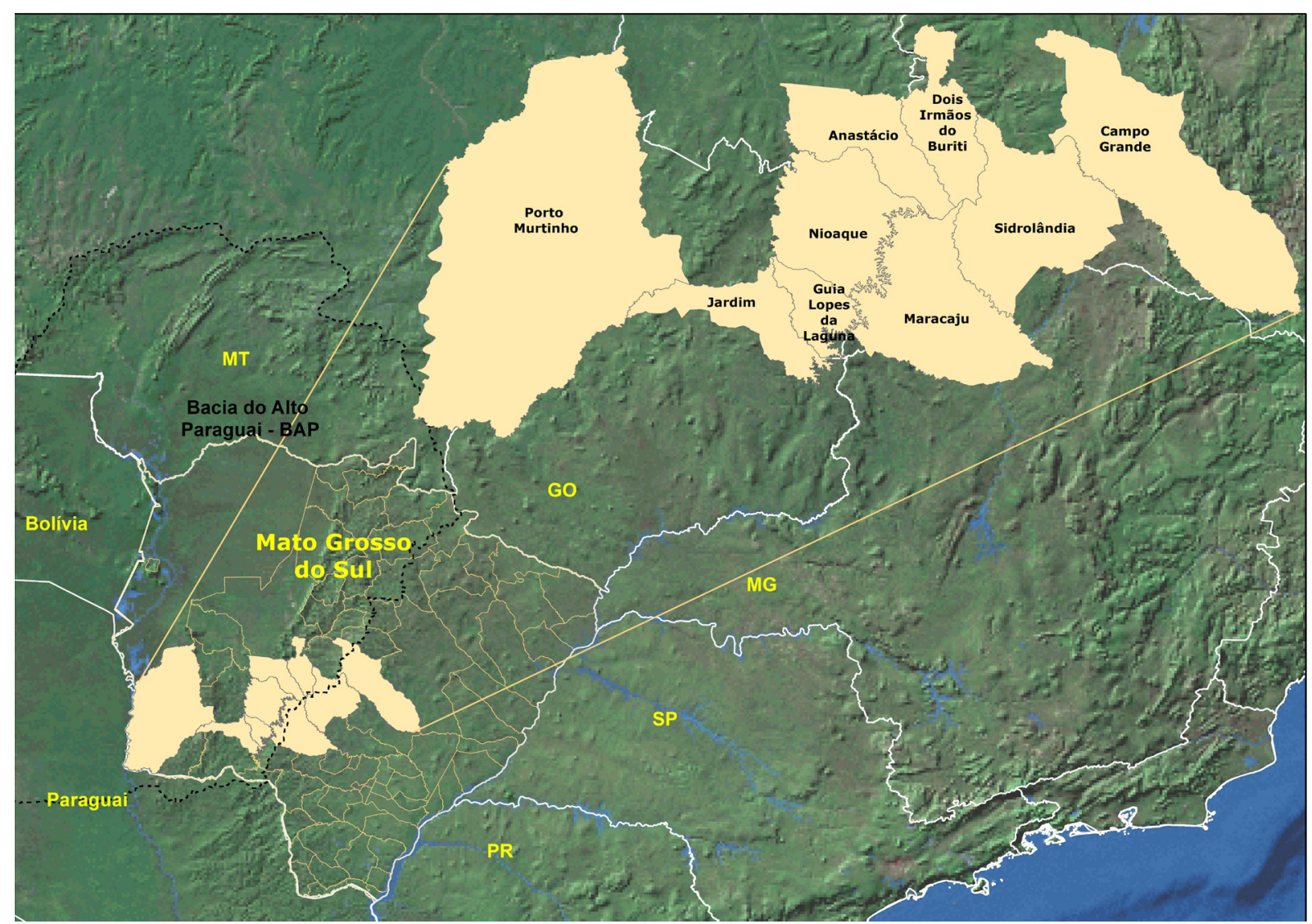

Fonte: Elaborado pelos autores.

O estudo baseou-se nos resultados obtidos no mapeamento do uso e ocupação do solo da Bacia do Alto Paraguai (2016), que consistiu de uma interpretação das imagens de satélite e a avaliação das áreas naturais, o trabalho foi realizado pelo processo híbrido, que consiste na classificação não-supervisionada, associação e validação das classes de modo manual. As imagens foram adquiridas do satélite Landsat 8 sensor OLI, através do Serviço Geológico dos Estados Unidos (USGS), e corresponderam ao período de seca. Para distinção entre uso antrópico e uso natural, foi realizada a classificação e reclassificação do índice de vegetação de diferença normalizada (NDVI). Foi efetuado o reagrupamento das fisionomias vegetais, sendo quatro classes naturais em função da proximidade quanto aos aspectos fitogeográficos da vegetação: formações florestais - FF, savana gramínea - SG, vegetação com influência fuvial - VF e área natural de manejo - ANM.

A formação florestal (FF) engloba 23 categorias (Tabela 1), incluindo as florestas estacionais deciduais, formação aluvial com localização nas planícies e ao longo dos rios, apresenta árvores altas e arbustos no estrato inferior, árvores densamente dispostas e árvores de pequeno porte distribuídas e dispostas em meio à vegetação contínua de porte arbustivo e herbáceo. 
Tabela 1 - Fisionomia vegetal do grupo Formações Florestais

\begin{tabular}{ll}
\hline $\mathrm{Ca}$ & Floresta Estacional Decidual Aluvial \\
$\mathrm{Cb}$ & Floresta Estacional Decidual de Terras Baixas \\
$\mathrm{Cs}$ & Floresta Estacional Decidual Submontana \\
$\mathrm{Fa}$ & Floresta Estacional Semidecidual Aluvial \\
$\mathrm{Fb}$ & Floresta Estacional Semidecidual de Terras Baixas \\
$\mathrm{Fs}$ & Floresta Estacional Semidecidual Submontana \\
$\mathrm{SN}$ & Savana Florestada/Floresta Estacional \\
$\mathrm{SNc}(\mathrm{Sd}+\mathrm{Fs})$ & Savana Florestada/Floresta Estacional Semidecidual (contato) \\
$\mathrm{SNc}(\mathrm{Sd}+\mathrm{Cs})$ & Savana Florestada/Floresta Estacional Decidual (contato) \\
$\mathrm{Sd}$ & Savana Florestada \\
$\mathrm{Sd}+\mathrm{Cs}$ & Savana Florestada/Floresta Estacional Decidual \\
$\mathrm{Sd}+\mathrm{Fs}$ & Savana Florestada/Floresta Estacional Semidecidual \\
$\mathrm{Sd}+\mathrm{Sa}$ & Savan Florestada/Savana Arborizada \\
$\mathrm{Sd}+\mathrm{Sg}$ & Savana Florestada/Savana Gramíneo \\
$\mathrm{Sd}+\mathrm{Spf}$ & Savana Florestada/Savana Parque \\
$\mathrm{SNt}(\mathrm{SCt})$ & Savana/Floresta Estacional Decidual (transição) \\
$\mathrm{SNt}(\mathrm{SFt})$ & Savana/Floresta Estacional Semidecidual (transição) \\
$\mathrm{Sa}$ & Savana Arborizada \\
$\mathrm{Sa+Sd}$ & Savana Arborizada/Savana Florestada \\
$\mathrm{Sa}+\mathrm{Sg}$ & Savana Arborizada/Savana Gramíneo \\
$\mathrm{Sa}+\mathrm{Sp}$ & Savana Arborizada/Savana Parque \\
$\mathrm{Saf}$ & Savana Arborizada com floresta galeria \\
$\mathrm{Sas}$ & Savana Arborizada sem floresta galeria \\
\hline
\end{tabular}

Fonte: Bacia do Alto Paraguai (2017).

A Savana gramínea (SG) apresenta espécies arbóreas, tendo como característica principal o aspecto graminóide, normalmente ocorrendo em áreas de inundações periódicas ou permanentes, apresentadas na Tabela 2.

Tabela 2 - Fisionomia vegetal do grupo Savana Gramínea.

\begin{tabular}{ll}
\hline Sg & Savana Gramíneo-Lenhosa \\
Sg+Sa & Savana Gramíneo-Lenhosa/Savana Arborizada \\
Sg+Sd & Savana Gramíneo-Lenhosa/Savana Florestada \\
Sgf & Savana Gramíneo-Lenhosa com floresta galeria \\
Sgs & Savana Gramíneo-Lenhosa sem floresta galeria \\
Sp & Savana Parque \\
Sp+Sa & Savana Parque/Savana Arborizada \\
Sp+Sg & Savana Parque/Savana Gramíneo \\
Spf & Savana Parque com floresta galeria \\
Spf+Sd & Savana Parque/Savana Florestada \\
Sps & Savana Parque sem floresta galeria \\
Vs & Vegetação Secundária \\
rsh & Refúgio \\
\hline
\end{tabular}

Fonte: Bacia do Alto Paraguai (2017). 
A Vegetação com influência fuvial (VF) é composta por vegetação de porte arbóreo e formações pioneiras como brejos, cambarazal, paratudal, carandazal, localizadas ao longo dos cursos de água e em áreas de depressões que acumulam água, apresentadas na Tabela 3.

Tabela 3 - Fisionomia vegetal do grupo Influência Fluvial.

\begin{tabular}{ll}
\hline $\mathrm{NPt}(\mathrm{F}+\mathrm{Pa})$ & Floresta Estacional/Pioneira (transição) \\
$\mathrm{P}$ & Formações Pioneiras \\
$\mathrm{Pa}$ & Formações Pioneiras com influência fluvial e/ou lacustre \\
$\mathrm{SP}$ & Savana/Pioneira \\
$\mathrm{SPt}(\mathrm{S}+\mathrm{Pa})$ & Savana/Formações Pioneiras (transição) \\
$\mathrm{TPt}(\mathrm{T}+\mathrm{Pa})$ & Savana-Estépica/Formações Pioneiras (transição) \\
\hline
\end{tabular}

Fonte: Bacia do Alto Paraguai (2017).

Área Natural de Manejo (ANM) é área com predominância de campos naturais, que são utilizadas para o desenvolvimento da atividade, a textura e a rugosidade são elementos fundamentais para a identificação da classe. As classes de uso antrópico foram agricultura - Ac, pastagem - Ap, influência por mineração - Im, influência urbana - lu, queima - Qmd, reflorestamento - R. Por fim a classe de água compreende os córregos, corixos, vazantes, baías.

A validação dos dados foi realizada com base em imagens do próprio satélite Landsat 8 e imagens de alta resolução, por meio do índice Kappa, de dois modos: isto é, de coleta das amostras utilizando a área total da bacia hidrográfica e coleta das amostras carta a carta. No primeiro modo, índice calculado apresentou o valor de 0,8 e no segundo o índice apresentou o valor de 0,7. Conforme Landis e Koch (1960) a qualidade da classificação no intervalo de 0,6-0,8 é considerada muito boa.

\section{RESULTADOS E DISCUSSÃO}

A Figura 2 apresenta o NDVI, se faz possível identificar o uso natural, antrópico e a presença de água. Nota-se que grande parte dos municípios estão localizados na região de planalto, porção ao leste da BAP. Há um predomínio das classes de usos antrópicos, que se deve aos modelos de ocupação desenvolvido na bacia, onde ocorreu a substituição da vegetação nativa. 
Figura 2 - Índice de vegetação de diferença normalizada
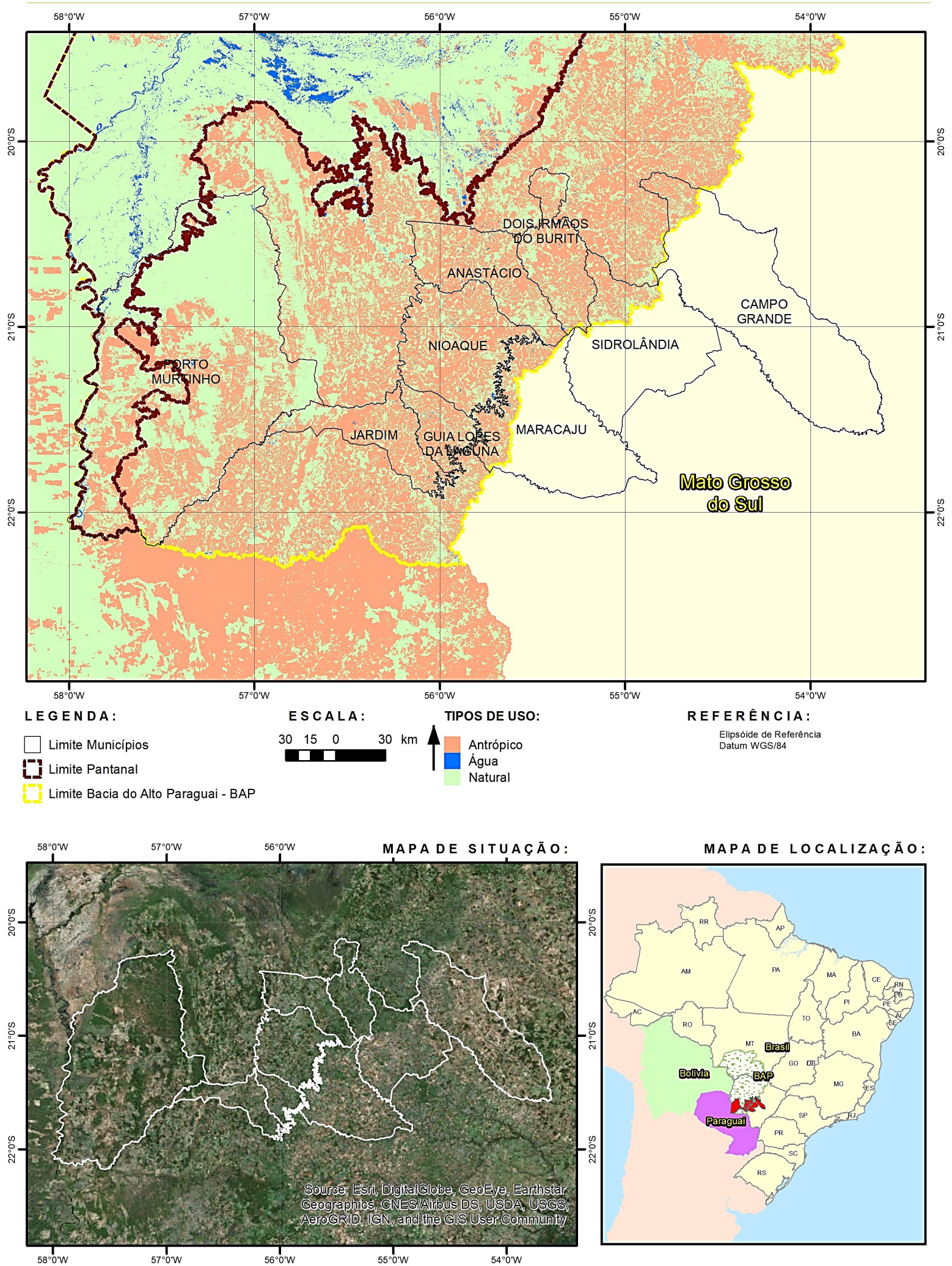

Fonte: Elaborado pelos autores. 
O Quadro 1 apresenta a quantificação das áreas naturais, antrópicas, classe água e território inseridos na BAP. Observa-se que Campo Grande é o município que possui a menor área inserida na bacia hidrográfica, seguido dos municípios de Sidrolândia e Maracaju. O município de Porto Murtinho apresenta a maior área natural, acima de 60\%. Os demais possuem em média 30\% de vegetação nativa. Com relação a área antrópica a maioria dos municípios possuem o uso antrópico acima de 60\%, exceto Bonito e Porto Murtinho, com respectivamente 55,59 e $33,80 \%$ de áreas dedicadas a essas atividades. Com relação às áreas alagadas, que representam os córregos, corixos, vazantes baías e salinas presentes, em média os municípios apresentam menos de $1 \%$ de áreas ocupadas pela água, a maior área ocupada por essa classe pertence ao município de Porto Murtinho, com 114,57 km².

Quadro 1 - Uso do Solo

\begin{tabular}{|c|c|c|c|c|c|c|c|c|c|}
\hline Município & $\begin{array}{l}\text { Área do } \\
\text { município }\end{array}$ & $\begin{array}{c}\text { Área } \\
\text { inserida } \\
\text { na BAP } \\
\left(\mathbf{k m}^{2}\right)\end{array}$ & $\%$ & $\begin{array}{l}\text { Natural } \\
\left(\mathrm{km}^{2}\right) \\
\end{array}$ & $\%$ & $\begin{array}{c}\text { Antrópico } \\
\left(\mathrm{km}^{2}\right)\end{array}$ & $\%$ & $\begin{array}{l}\text { Água } \\
\left(\mathrm{km}^{2}\right)\end{array}$ & $\%$ \\
\hline Anastácio & 2948,00 & 2948,00 & 100,00 & 1137,34 & 38,58 & 1792,21 & 60,79 & 18,45 & 0,63 \\
\hline Bonito & 4930,89 & 4930,89 & 100,00 & 2176,73 & 44,14 & 2740,89 & 55,59 & 13,26 & 0,27 \\
\hline $\begin{array}{l}\text { Campo } \\
\text { Grande }\end{array}$ & 8103,05 & 575,39 & 7,10 & 173,15 & 30,09 & 401,29 & 69,74 & 0,95 & 0,17 \\
\hline $\begin{array}{l}\text { Dois Irmãos } \\
\text { do Buriti }\end{array}$ & 2336,26 & 2336,26 & 100,00 & 828,33 & 35,46 & 1497,92 & 64,12 & 10,01 & 0,43 \\
\hline $\begin{array}{l}\text { Guia Lopes } \\
\text { da Laguna }\end{array}$ & 1209,96 & 1209,96 & 100,00 & 392,24 & 32,42 & 808,16 & 66,79 & 9,56 & 0,79 \\
\hline Jardim & 2200,03 & 2200,03 & 100,00 & 746,90 & 33,95 & 1442,43 & 65,56 & 10,70 & 0,49 \\
\hline Maracaju & 5298,62 & 1293,78 & 24,42 & 441,52 & 34,13 & 850,01 & 65,70 & 2,24 & 0,17 \\
\hline Nioaque & 3921,95 & 3921,94 & 100,00 & 1415,72 & 36,10 & 2484,33 & 63,34 & 21,89 & 0,56 \\
\hline $\begin{array}{c}\text { Porto } \\
\text { Murtinho }\end{array}$ & 17699,76 & 17699,76 & 100,00 & 11602,06 & 65,55 & 5983,13 & 33,80 & 114,57 & 0,65 \\
\hline Sidrolândia & 5288,22 & 948,44 & 17,93 & 359,55 & 37,91 & 586,24 & 61,81 & 2,65 & 0,28 \\
\hline
\end{tabular}

Fonte: adaptado de Bacia do Alto Paraguai (2017).

Avaliando parâmetros biofísicos de superfície do Bioma Pantanal com a aplicação de geotecnologias, Andrade et al. (2012) concluíram que resultados foram consistentes com dados de literatura para os diferentes usos e cobertura da terra, mostrando o potencial de geotecnologias para a compreensão da dinâmica de processos biofísicos. Buscando analisar a qualidade observada nas imagens em diferentes compartimentos do relevo, além da conectividade entre cenas, Kalaf et al. (2013), utilizaram imagens do satélite Landsat 8 que compreenderam o Estado do Rio de Janeiro. Verificou a exatidão do posicionamento com bases em grande escala, como também em diferentes condições de relevo, além da alta conectividade entre as cenas, evidenciando a elevada qualidade das imagens desse satélite.

Soares, Gonçalves e Fonseca (2011) buscaram mapear e analisar o uso e ocupação do solo na região do município de Santarém, PA, através de imagens Landsat 5, a partir do algoritmo de máxima verossimilhança e com isso conseguiram distinguir a classes de uso na área de estudo, pode-se identificar a presença de nuvens, solos, água, área agrícola, floresta nativa, gramínea 
e sombra. Também utilizando imagens do satélite Landsat 5 Demarchi, Piroli e Zimback (2011) observaram evolução temporal do uso do solo no município de Santa Cruz do Rio Pardo, SP, por meio a classificação supervisionada, no qual comparou os índices de vegetação NDVI e SAVI e para verificação a exatidão do mapeamento aplicaram o índice Kappa. Os índices de vegetação mostraram-se suficientes para avaliação da cobertura vegetal e, de modo geral, conseguiram distinguir as classes presentes na área de estudo, apresentando um índice Kappa entre 0,4 a 0,7 , considerados satisfatórios.

A Figura 3 apresenta as classes de uso antrópicos e natural. Nela podem ser identificados os usos antrópicos como agropecuária, pastagens, influência de mineração, influência urbana e reflorestamento. Já as áreas naturais compreenderam a savana gramínea e formações florestais, como também a presença de água.

O Quadro 2 apresenta a quantificação por municípios dos usos antrópico e natural e a presença de água. Observa- se que grande de parte dos usos antrópicos estão relacionados a áreas de pastagens, sendo o município de Porto Murtinho o que possui um a maior área com 5948,97 $\mathrm{km}^{2}$, e, o menor, o município de Maracaju apresentando uma área de 161,96 km². Considerando as áreas destinadas à agricultura Maracaju possui o destaque com $688,05 \mathrm{~km}^{2}$. Com relação às áreas que apresentam influência de mineração, Guia Lopes da Laguna dispõe de uma área 8,21 $\mathrm{km}^{2}$ devido a ocorrências minerais como cobre, areia, calcário, como também Nioaque tem uma área de 0,24 km², onde há a extração de mineral não-metálico, como a areia. Nota-se que apenas o município de Porto Murtinho apresenta uso antrópico relacionado ao reflorestamento, com 10,2 km². Quanto aos usos naturais a formação florestal possui as maiores áreas comprada a savana gramínea em todos os municípios, sendo Porto Murtinho o município que dispões das maiores áreas natural, sendo 8919,91 km² de FF e 2671,95 km² de SG. 
Figura 3 - Uso do solo nos municípios
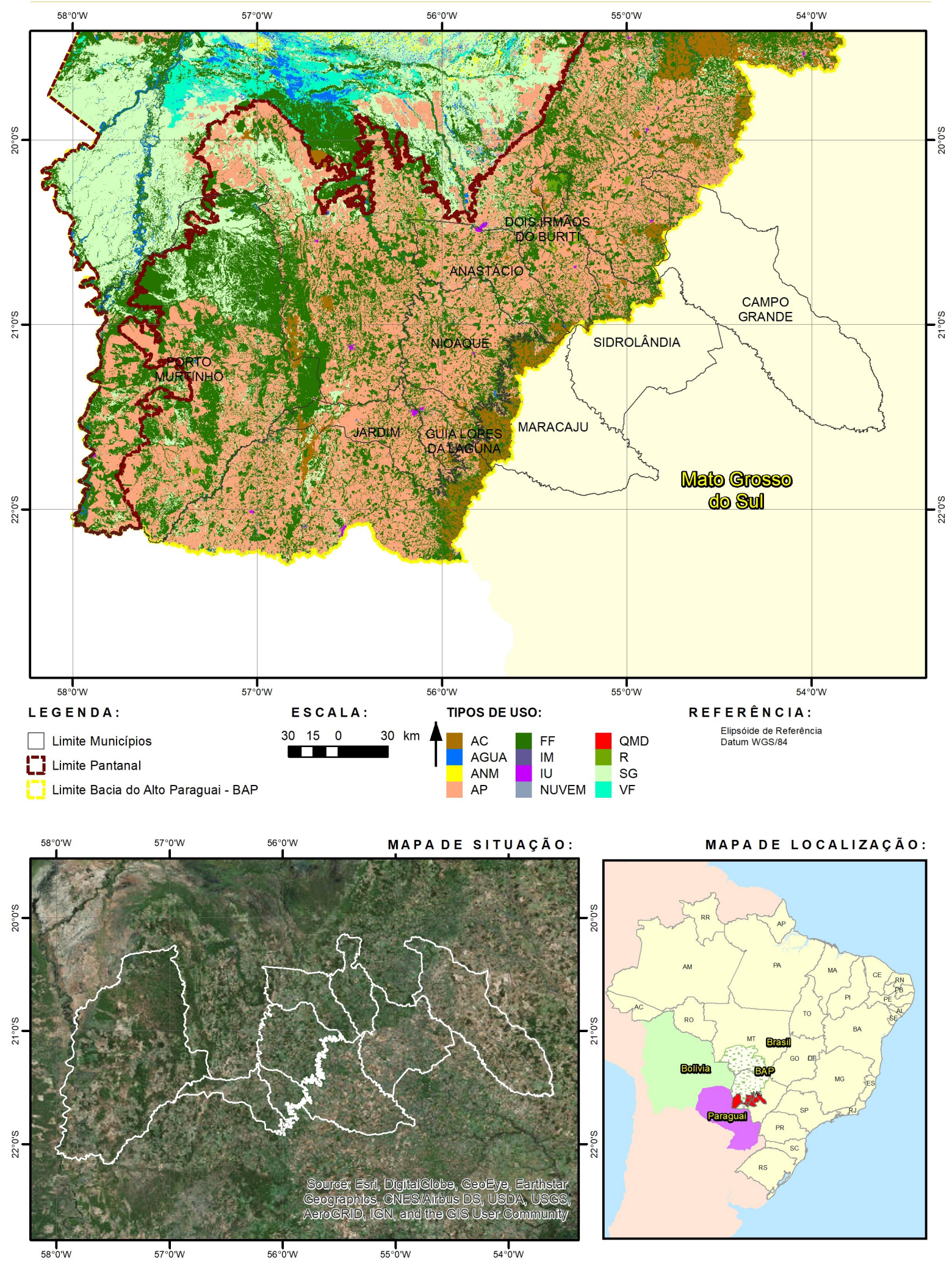

Fonte: Elaborado pelos autores.

Barros e Silva (2015), avaliando o uso da terra na bacia hidrográfica do alto rio Paraguai no Brasil, verificaram que as áreas destinadas às lavouras, sendo lavouras permanentes, temporárias, áreas de forrageiras para corte e área com cultivo de flores e mudas. Grande parte dos 
municípios possuem áreas destinadas a pastagens. Entre os seus usos específicos estão as áreas de pastagem natural e de pastagem plantada, degradada e não degradada. Nas áreas de matas e florestas as categorias presentes foram áreas ou florestas naturais destinadas, matas naturais existentes, área de silvicultura e área de sistemas florestais.

Quadro 2 - Áreas naturais e antrópicas

\begin{tabular}{|c|c|c|c|c|c|c|c|}
\hline \multirow{2}{*}{ Município } & \multicolumn{5}{|c|}{ Antrópico $\left(\mathrm{Km}^{2}\right)$} & \multicolumn{2}{|c|}{ Natural $\left(\mathrm{Km}^{2}\right)$} \\
\hline & Ac & Ap & lu & Im & $\mathbf{R}$ & FF & SG \\
\hline Anastácio & 76,34 & 1707,68 & 8,19 & - & - & 1025,57 & 11,77 \\
\hline Bonito & 181,49 & 2553,73 & 5,68 & - & - & 2057,65 & 119,09 \\
\hline Campo Grande & 8,31 & 392,98 & - & - & - & 173,15 & - \\
\hline Dois Irmãos do Buriti & 123,46 & 1372,62 & 1,85 & - & - & 820,27 & 8,07 \\
\hline Guia Lopes da Laguna & 77,93 & 718,42 & 3,6 & 8,21 & - & 392,24 & - \\
\hline Jardim & 60,74 & 1371,23 & 10,46 & - & - & 693,41 & 53,48 \\
\hline Maracaju & 688,05 & 161,96 & - & - & - & 441,52 & - \\
\hline Nioaque & 46,41 & 2436,22 & 1,45 & 0,24 & - & 1363,3 & 52,42 \\
\hline Porto Murtinho & 29,39 & 5948,97 & 4,76 & - & 10,2 & 8919,91 & 2671,95 \\
\hline Sidrolândia & 107,05 & 476,39 & 2,8 & - & - & 359,55 & - \\
\hline
\end{tabular}

Fonte: adaptado de Bacia do Alto Paraguai (2017).

Avaliando a dinâmica da agricultura na bacia do alto Paraguai Coutinho et al. (2016), identificaram áreas agrícolas para produção de grãos ocupava porção a leste do planalto da bacia, já áreas agrícolas para produção de cana-de-açúcar estavam fortemente concentradas na porção norte do planalto da BAP. Cechim Júnior et al. (2017), mapeando culturas agrícolas de soja e milho, consideradas culturas de verão, na BAP através da série temporada EVI / MODIS, verificaram que num período de 16 anos houve um aumento de 40,6\% da participação da agricultura anual na bacia.

\section{CONCLUSÃO}

O emprego das imagens Landsat-8, juntamente com o processo híbrido de classificação, propiciou a identificação e elaboração do mapeamento temático das classes de uso e ocupação do solo. Através da identificação do uso natural e antrópico, constatou-se que a classe de uso antrópico é de maior predominância, no qual em média 60\% dos municípios tiveram parte de sua vegetação nativa substituídas por monoculturas e pastagens exóticas.

Na classificação pode ser notado o domínio de áreas destinada as pastagens, bem como áreas agrícolas nos usos antrópicos. Nas áreas de vegetação nativa as classes de vegetação presentes são a formação florestais e savana gramínea. Devido ao estudo analisar somente o período de seca, e grande parte dos municípios estarem inseridos na região do planalto da bacia, a classe água não possuiu uma representatividade significativa.

\section{REFERÊNCIAS}

ANDRADE, R. G.; SEDIYAMA, G. C.; PAZ, A. R.; LIMA, E. P.; FACCO, A. G. Geotecnologias aplicadas à avaliação de parâmetros biofísicos do Pantanal. Pesquisa Agropecuária Brasileira, Brasília, v. 47, n. 9, p. 1227-34, 2012. 
ANTUNES, J. F. G.; ESQUERDO, J. C. D. M.; LAMPARELLI, R. A. C. Temporal dynamic monitoring of four vegetation cover of Pantanal using the Wavelet Transform applied to a time-series of EVI/MODIS data. Geografia, Rio Claro, v. 36, p. 173-85, 2011.

BACIA DO ALTO PARAGUAI USO E OCUPAÇÃO DO SOLO-2016. Relatório técnico. Brasília: WWF-Brasil; Universidade Católica Dom Bosco; Fundação Tuiuiú, 2017. 39 p.

BARROS, C. F.; SILVA, J. S. V. Uso da terra na bacia hidrográfica do alto rio Paraguai no Brasil. In: XI MOSTRA DE ESTAGIÁRIOS E BOLSISTAS DA EMBRAPA INFORMÁTICA AGROPECUÁRIA, 9., Campinas, 10-12 nov. 2015. Resumos Expandidos [...]. Brasília, DF: Embrapa, 2015. p. 102-6.

CECHIM JÚNIOR, C.; ANTUNES, J. F. G; JOHANN, J. A.; ESQUERDO, J. C. D. M. Mapeamento de culturas agrícolas de verão na Bacia do Alto Paraguai por meio de séries temporais de EVI/MODIS. Geografia, Rio Claro, v. 42, n. 3 (Especial), p. 129-43, set./dez. 2017.

COUTINHO, A. C.; BISHOP, C.; ESQUERDO, J. C. D. M.; KASTENS, J. H.; BROWN, J. Dinâmica da agricultura na Bacia do Alto Paraguai. In: SIMPÓSIO DE GEOTECNOLOGIA NO PANTANAL. Cuiabá, 2016. Anais [...]. Cuiabá:: Embrapa Informática Agropecuária/INPE, 2016. p. 623-332.

DEMARCHI, J. C.; PIROLI, E. L.; ZIMBACK, C. R. L. Análise temporal do uso do solo e comparação entre os índices de vegetação NDVI e SAVI no município de Santa Cruz do Rio Pardo-SP usando imagens Landsat-5. Ra'e ga- O Espaço Geográfico em Análise, v. 21, p. 234-71, 2011.

FERREIRA, A. L. S; PASSA, M. C. O uso de geotecnologia aplicada ao monitoramento de desmatamento do Pantanal Mato-grossense. Advances in Forestry Science, Cuiabá, v. 2, n. 2, p. 41-7, 2015.

KALAF, R.; BRASILEIRO, R.; CARDOSO, P. V.; CRUZ, B. M. C. Landsat 8: Avanços para mapeamento em mesoescala. In: CONGRESSO BRASILEIRO DE GEOPROCESSAMENTO, 4., Rio de Janeiro, 11-13 set. 2013. Anais [...]. Rio de Janeiro, 2013

LANDIS, R.; KOCH, G. G. The measurement of observer agrément for categorical data. Biometrics, v. 33, n. 1, p.159-74, mar. 1977.

MACEDO, M. R. A. Uso de geotecnologias na identificação e mapeamento dos atores do desmatamento na frente pioneira de São Félix do Xingu-PA. Belém: Universidade Federal do Pará, 2009.

MIRANDA, C. S.; GAMARRA, R. M.; MIOTO, C. L.; SILVA, N. M.; CONCEIÇÃO FILHO, A. P.; POTT, A. Analysis of the landscape complexity and heterogeneity of the Pantanal wetland. Brazilian Journal of Biology, $\mathrm{v}$. 78, n. 2, p. 318-27, 2018.

PESSOA, S. P. M., GALVANIN, E. A. S.; KREITLOW, J. P; S.; NEVES, M. A. S., NUNES, J. R. S.; ZAGO, B. W. Análise Espaço-Temporal da Cobertura Vegetal e Uso da Terra na Interbacia do Rio Paraguai Médio-MT, Brasil. Revista Árvore, Viçosa, MG, v. 37, n. 1, p. 119-28, 2013.

PONZONI, F. J.; REZENDE, P. A. C. Caracterização espectral de estágios sucessionais de vegetação secundária arbórea em Altamira (PA), através de dados orbitais. Revista Árvore, Viçosa, MG, v. 28, n. 4, p. 535-45, 2004.

ROSA, F. R.; LOPES, I. R.; SANCHES, V. Q. A.; REZENDE, E. K. Distribuição de caranguejos Trichodactylidae (Crustacea, Brachyura) em alagados do Pantanal Mato-Grossense (Brasil) e sua correlação com a proximidade do rio Cuiabá e cobertura vegetal. Papéis Avulsos de Zoologia, São Paulo, v. 49, n. 24, p. 311-17, 2009.

ROSA, R. Geotecnologias na geografia. Revista do Departamento de Geografia, São Paulo, v. 16, p. 81-90, 2005. 
SOARES, S. C; GONÇALVES, J. P. D.; FONSECA, L. M. G. Mapeamento e análise multitemporal do uso e ocupação do solo em região do município de Santarém-PA através de imagens Landsat 5-TM. In: Simpósio Brasileiro de Sensoriamento Remoto - SBSR,15., Curitiba, 30 abr.- 5 maio. 2011. Anais [...]. Curitiba, PR: INPE.

\section{Sobre os autores:}

Mariana Antonio de Souza Pereira - Graduada em Engenharia Sanitária e Ambiental pela Universidade Católica Dom Bosco. E-mail: marianapereira.esa@gmail.com, Orcid: http://orcid.org/0000-0002-9415-5374

Fernando Jorge Corrêa Magalhães Filho - Doutorado em Saneamento Ambiental e Recursos Hídricos pela Universidade Federal de Mato Grosso do Sul (UFMS). Professor na Universidade Católica Dom Bosco (UCDB). E-mail: fernando@ucdb.br, Orcid: http://orcid.org/0000-0001-5447-0137

Ana Paula Silva Teles - Mestrado em Ciências Ambientais e Sustentabilidade Agropecuária pela Universidade Católica Dom Bosco (UCDB). Professora na Universidade Católica Dom Bosco (UCDB). E-mail: rf7792@ucdb.br, Orcid: http://orcid.org/0000-0003-4689-0590

Fabio Martins Ayres - Doutorado em Meio Ambiente e Desenvolvimento Regional pela Universidade Anhanguera-Uniderp. Professor na Universidade Católica Dom Bosco (UCDB). E-mail: fabiomartinsayres@gmail.com, Orcid: http://orcid.org/0000-0003-0324-8880 